\title{
Possible lattice organs in Cretaceous Thylacocephala
}

\author{
Sven Lange \& Fredérick R. Schram \\ Institute for Biodiversity and Ecosystem Dynamics, University of Amsterdam, Mauritskade 57, \\ 1092 AD Amsterdam, Netherlands
}

Key words: Thylacocephala, fossils, lattice organs, Thecostraca, Cirripedia, Ascothoracida, Crustacea, Cretaceous.

\begin{abstract}
Structures, reminiscent of the lattice organs in thecostracan crustaceans, are described from the carapace cuticle of Cretaceous thylacocephalans. The new lattice organ like structures occur in pairs along the dorsal midline. While these have a similar outline to true lattice organs, they seem to lack pores and do not occur in the highly apomorphic pattern found in thecostracans. These discrepancies do not easily support earlier ideas of a position of the thylacocephalans within the thecostracans. The significance of the possible lattice organs for inferring a relationship between thylacocephalans and thecostracans is discussed.
\end{abstract}

\section{Contents}

$\begin{array}{ll}\text { Abstract } & 159 \\ \text { Introduction } & 159 \\ \text { Lattice organs: a review } & 160 \\ \text { Materials and methods } & 160 \\ \text { Results } & 161 \\ \quad \text { Presence and position of possible lattice organs } & 161 \\ \quad \text { Morphology of possible lattice organs in light } & \\ \quad \text { microscopy } & 163 \\ \quad \text { Morphology of possible lattice organs in SEM } & 163 \\ \text { Reconstruction of the morphology of possible lattice } & \\ \quad \text { organs } & 165 \\ \text { Discussion } & 166 \\ \text { Acknowledgements } & 168 \\ \text { References } & 168\end{array}$

\section{Introduction}

Arthropod fossils now placed within the higher taxon Thylacocephala have been known since the 19 th century. It is only recently that their unique form has come to be recognized (Pinna et al. 1982; Secretan 1983; Briggs \& Rolfe 1983). Typically a large carapace envelops the entire body. This carapace covers the major part of the head and trunk, thus obscuring potentially important information such as segmentation. Out from under the carapace protrude two sets of limbs (see Secretan 1985; Rolfe 1985): a set of three pairs of sub-chelate raptorial limbs, and another set forming a posterior battery of usually eight (but sometimes more) small swimming limbs. Recently, Lange et al. (2001) described another set of limbs corresponding to antennules and antennae. In addition to these limbs, a pair of large compound eyes often bulge out from the anterior margin of the carapace. A row of featherlike gills regularly appears near the middle region of the body under the carapace (Rolfe 1985; Secretan \& Riou 1983; Schram et al. 1999). Thylacocephala are known from the Silurian (Mikulic et al. 1985; Van den Brugghen et al. 1997) through to the Cretäceous (Schram et al. 1999).

The taxonomic affinities of the thylacocephalans remained 'uncertain' (Rolfe 1992), although most authors at least implied some kind of crustacean affinity. With the recent description of two pairs of antennae in the Cretaceous thylacocephalan Thylacocephalus cymolopos Lange et al. 2001, the possible affinity with Crustacea has been strengthened. However, determination of a crustacean sister group for the Thylacocephala remains vexing. A number of possible and contradictory crustacean relatives have, nevertheless, been suggested based on various morphological similarities. Secretan (1983) considered the possibility of phyllocarids, mala- 
costracans and conchostracans as sister taxa. Schram (1990) drew comparisons with malacostracans based on the presence of large sub-chelate raptorial limbs (stomatopods), large eyes and well-developed gills (many eumalacostracans), and even noted some potential points of similarity between thylacocephalans and remipedes. Arduini et al. (1980) first drew attention to similarities with thecostracan cirripedes, and this was reinforced by Pinna et al. (1985). However, Rolfe (1985) and Schram (1990) rejected this possibility, perhaps too precipitously since Schram et al. (1999: plate 3, fig. 7) illustrated the presence of elongate cuticular structures that were evocative of lattice organs, a distinct thecostracan apomorphy found on the carapace of some free swimming stages of thecostracan larvae (Schram et al. 1999).

\section{Lattice organs: a review}

Thecostracan lattice organs were first described by Elfimov (1986). Their status as synapomorphies for the Cirripedia and the Ascothoracida (in the latter group they were initially dubbed cardiac organs, but Jensen et al. (1994a) later identified them as lattice organs on grounds of homology) was firmly established by Itô \& Grygier (1990) and Jensen et al. (1994a). Lattice organs have been found in the cyprid larvae of thoracican, acrothoracican, and rhizocephalan Cirripedia as well as in larval stages of Ascothoracida (Jensen et al. 1994a) and recently also in Y-larval Facetotecta (Høeg \& Kolbasov 2002). The extant crustacean parasite Tantulocarida as well as the Cambrian Bredocaris have been brought forward as potential sister groups of the Thecostraca (Walossek et al. 1996; Walossek \& Müller 1998), but both groups definitely lack lattice organs. However, within the Thecostraca the number, position and anatomy of lattice organs constitute systematically valuable characters (Høeg \& Kolbasov 2002).

In thecostracans, the lattice organ complex normally forms characteristic constellations of two clusters containing all together five pairs of lattice organs. Typically, the anterior cluster contains two pairs while the posterior usually includes three pairs. However, some species have a reduced number of lattice organs while a varying number of "extra" pore fields have been registered in the carapace of other species. Such 'extra' fields resemble lattice organs but display a more irregular layout and lack the terminal pores found in most "real" lattice organs (Jensen et al. 1994a).

The outline of the lattice organs varies from very elongate to roundish; and from a deep depression that contains a central raised smooth keel, to simple flat pore fields in level with the surrounding carapace cuticle. Intermediates of these principal types may have less pronounced keels with a reticulated surface comparable to the pore fields. One so-called terminal pore is often associated with each lattice organ. A rim of cuticle sometimes delimits the lattice organs (Jensen et al. 1994a; Jensen et al. 1994b). Often they are minute structures of 5-10 $\mu \mathrm{m}$ length and 1-2 $\mu \mathrm{m}$ width but dimensions vary with species and some rather 'gigantic' lattice organs approach $50 \mu \mathrm{m}$ length or $10 \mu \mathrm{m}$ width (including the surrounding rim) in some of the larger lepadid species (Jensen et al. 1994a).

New evidence demonstrates that the lattice organs are derived setae (Rybakov et al. in press) presumably with a chemosensory function (Høeg et al. 1998). Dendrites from sensory cells project into the cuticle and terminate in proximity to the pores. The larger terminal pore seems the most likely pathway for molecules to reach the sensory elements in Facetotecta and Ascothoracida. In Thoracica and Rhizocephala, the many small pores of the pore field may facilitate diffusion towards the sensory elements. These pores reside in the exocuticle with the thin epicuticle coating the walls and the bottom of the pores. In Acrothoracica, minute pores penetrate the epicuticle but not the underlying exocuticle. The possession of numerous pores may be autapomorphic for the cirripedian lattice organs (Høeg et al. 1998; Høeg \& Kolbasov 2002).

\section{Materials and methods}

Four Cretaceous thylacocephalan species were examined: Protozoea hilgendorfi Dames, 1886; $P$. damesi Roger, 1946; Pseuderichthus cretaceus Dames, 1886, and Thylacocephalus cymolopos Lange et al. (2001).

Series of possible lattice organs were found in eight specimens of: Protozoea hilgendorfi: [BM: J 469-1, J 622-1; OR 
Table 1. Information on thylacocephalan fossils possessing well preserved series of lattice like organs including length $\left(^{*}\right.$ carapace length without rostrum and posterior spines, in mm); body type (**according to Schram et al., 1999); position of organs (ant anterior, mid - mid dorsal, post:- posterior); number of organs and distance between neighboring organs (in mm).

\begin{tabular}{|c|c|c|c|c|c|}
\hline$P_{x}$ hilgendorft & Carapace length & $\begin{array}{l}\text { Body type** } \\
\text { mm (estimated*) }\end{array}$ & $\begin{array}{l}\text { Position of series } \\
\text { along midline }\end{array}$ & $\begin{array}{l}\text { Number of llo's } \\
\text { in each series }\end{array}$ & $\begin{array}{l}\text { Average distance } \\
\text { between illo's }\end{array}$ \\
\hline \multirow[t]{3}{*}{ BM J469-1 } & (40) & globose & ant & 3 & 0.5 \\
\hline & & & mid & 10 & 0.55 \\
\hline & & & most & 7 & 0.85 \\
\hline \multirow[t]{3}{*}{ BM J622-1 } & 78 & elongate & ant & 12 & 0.5 \\
\hline & & & mid & 7 & 0.85 \\
\hline & & & post & 11 & 1.5 \\
\hline BM OR 59245 (2)-1 & 44 & elongate & mid & $\sim 20$ & 0.5 \\
\hline BM OR 59245 (3)-1 & (50) & intermediate & post & 12 & 0.82 \\
\hline BM OR 59554 (3) & (32) & globose & mid - post & $15-20$ & $0.4-0.5$ \\
\hline MB A 693.3 & (24) & globose & mid & $\sim 13$ & 0.6 \\
\hline MSNM il2172 & 42 & intermediate & mid & 5 & 0.8 \\
\hline MSNM i20556 & (30) & globose & post & $4-5$ & 0.7 \\
\hline
\end{tabular}

P. damesi

post .

8

$0.2-0.3$

59245 (2)-1, (3)-1, OR 59554 (3). MB: A 693.3. MSNM: i12172, i20556] and one specimen of $P$, damesi [BM: OR 59672 (4)] (see Table 1).

Similar structures occurred sporadically in some four specimens of $P$, hilgendorf: [BM: PI IC 82; In 42507a; OR 59672 (16)] and an additional specimen MSNM: 17586-3, which is of uncertain thylacocephalan affinity.

Further possible lattice organs were noted, but their poor preservation prevents unequivocal identification: $P$. hilgendor $f$ : [BM: PI IC 76, 83; In 48832 (2), (3); OR 59554 (2), OR 59672 (14), (15) and (24). MB: A 693.4, 693.5. MSNM: 17586-1]; $P$. damesi: [BM: IC 91-1; OR 59245 (4)-1, OR 59672 (25).]

A section (indicated in Fig. 1A) of the posterior carapace along the dorsal midline of one especially well-preserved specimen (BM: J 622-1) was carefully removed. The section containing four pairs of possible lattice organs was subjected to standard high voltage SEM (JEOL JSM-35C), and images were saved in the Semaphore digital image storage system.

In addition, specimens of the Jurassic thylacocephalan Dollocaris ingens van Straelen, 1923 were examined. Structures reminiscent of possible lattice organs were noted on two specimens (MNHN: R.50930 and R.50937).

Specimen repositories are abbreviated as follows: BM - The Natural History Museum, London; MB - Museum für Naturkunde, Berlin; MNHN - Museum Nationale d'Histoire Naturelle, Paris; MSNM - Museo Civico di Storia Naturale, Milan.

\section{Results}

\section{Presence and position of possible lattice organs}

Our putative lattice organs were best observed in $P$. hilgendorfi. Eight specimens of this species preserved series of potential lattice organs, while only one $P$. damesi preserved such a series. Scattered organs of this type were observed on an additional four specimens, whereas another 14 specimens showed evidence of what could very well also be traces of such structures. In several fossils (BM J 622-1; BM OR 59245 (2)-1 and (3)-1), the bilateral symmetrical arrangement of the possible lattice organs was observed. They occur in pairs in the immediate vicinity of the dorsal hinge-, or midline with one member of each pair on the right valve and the other member of the pair on the left (Fig. 1A-F).

Possible lattice organs were encountered anywhere along the dorsal midline of the carapace but were never detected on either the rostrum or the posterior spines. For instance in BM J 622, which best preserves the possible lattice organs, the dorsal midline is only properly exposed near the rostrum, in a few areas along the central part of the carapace and posteriorly for approximately one 

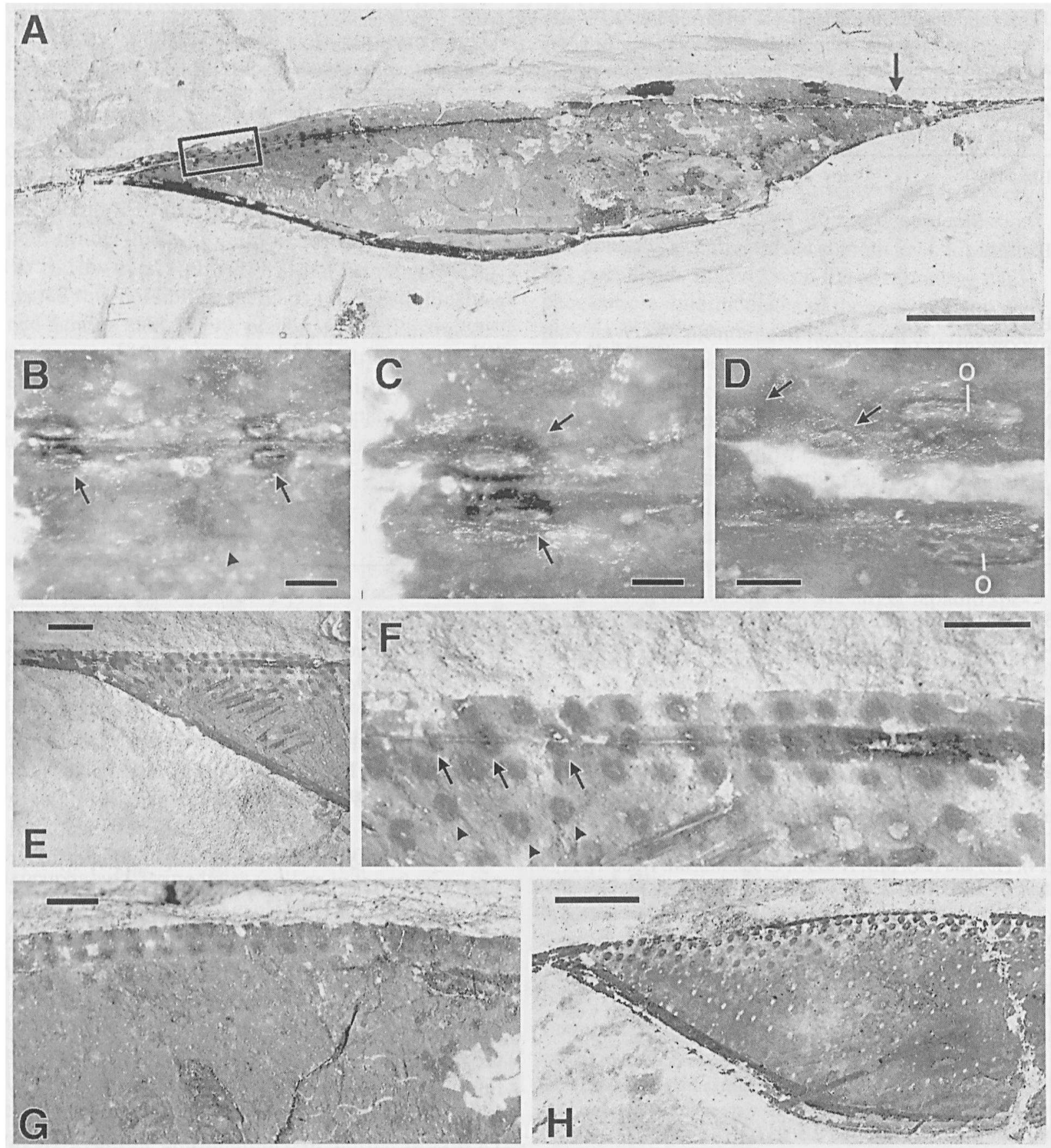

Fig. 1. Protozoea hilgendorfi. Anterior to the right. A-D, BM J 622-1. A, lateral view of the right side (as well as minor part of left side of carapace) of specimen with possible lattice organs on both sides of the hinge-line that marks the dorsal midline. Box indicates position of section that was subjected to SEM. (Arrow indicate locality of Fig. 1D). B, Part of the posterior midline (directly anterior to box in Fig. 1A) and two pairs of lattice like organs. Note also the circular pit organs (arrowhead). C, Posterior pair of lattice like organs from fig. 1B. shows the central elongated depressions and the surrounding dark rim. D, Smaller anterior possible lattice organs and a pair of slender, oblong structures found only in this position and only in one pair. Arrows indicate position of some possible lattice organs: o, oblong structures. E and F, BM OR 59245 (3)-1, posterior end with series of lattice like organs. F, in close up. Note also the numerous circular pit organs (arrowheads). G, BM OR 59554 (3), central part of dorsal midline with possible lattice organs along the margin. H, BM J 469-1, with possible lattice organs at the mid-and posterior part of the dorsal midline. Scale bars of $\mathrm{A}=$ $10 \mathrm{~mm} ; \mathrm{B}=400 \mu \mathrm{m} ; \mathrm{C}=100 \mu \mathrm{m} ; \mathrm{D}=500 \mu \mathrm{m} ; \mathrm{E}$ and $\mathrm{F}=2 \mathrm{~mm} ; \mathrm{G}$ and $\mathrm{H}=1 \mathrm{~mm}$. 
quarter of the entire length of the specimen (Fig. 1A). All these exposed stretches reveal possible lattice organs (Fig. 1B-C). Series of possible lattice organs are preserved along the midline in other specimens as well in various positions with respect to the body axis (Fig. 1E-H and Table 1). It consequently seems reasonable to assume that the possible lattice organs formed a complete series from rostrum to posterior spine, though none of the examined $P$. hilgendorf $i$ actually displayed such a complete series.

An obvious increment in the distance between neighboring possible lattice organs towards the posterior was observed (Table 1). In BM J 622-1 (Fig 1A-D), the first 12 pairs of organs are found within $5 \mathrm{~mm}$ (average distance between adjacent possible lattice organs less than $0.5 \mathrm{~mm}$ ). Near the center of BM J 622-1, another 7 possible lattice organs cover $4.5 \mathrm{~mm}$ (average distance $\sim 0.75 \mathrm{~mm}$ ), while the 11 pairs on the $15 \mathrm{~mm}$ near the posterior spine are found with an average distance from each other of approximately $1.5 \mathrm{~mm}$, rising to about 2 $\mathrm{mm}$ for the very last pairs. The same trend can be observed for specimen BM J 469-1, and also inferred from the average distances between pairs in other $P$. hilgendorfi (Tab. 1).

Apparently, the possession of possible lattice organs is restricted neither to individuals of a particular (large) size, nor to individuals of a certain body type. $P$. hilgendorf $i$ lengths range from 21.5 $-78 \mathrm{~mm}$ (Schram et al. 1999), and specimens with possible lattice organs span this range neatly (Tab. 1). The full length of specimen MB A 693.3 is estimated at about $24 \mathrm{~mm}$ (this specimen lacks the posteriormost part of its carapace), but there is no doubt that it belongs to the smallest known $P$. hilgendorfi. Specimen BM J 622-1 on the other hand is a 'giant' reaching $78 \mathrm{~mm}$ in length. Both specimens have possible lattice organs. Another important pattern of variation concerns the body type of $P$. hilgendorf $i$, which varies from elongate with a ratio of length to height of $8: 1$, to quite globose specimens with a ratio of 2.5:1 (Schram et al. 1999). Both elongate, globose and intermediary forms are represented among the specimens with possible lattice organs (Tab. 1).

\section{Morphology of possible lattice organs in light microscopy}

The possible lattice organs appear as oval spots of dark brown color clearly distinguishable from the surrounding light-brown cuticle of the carapace (Fig $1 \mathrm{~B}, \mathrm{C}$ and $\mathrm{F}$ ). The largest possible lattice organs, found posteriorly in BM J 622-1, measure $300 \times$ $150 \mu \mathrm{m}$. They consist of an outer dark rim with a width of $50 \mu \mathrm{m}$ or more, which surrounds an approximately $150 \times 50 \mu \mathrm{m}$ lighter central area. This elongated, occasionally slightly pear shaped, area is often delimited by a slightly raised ridge or wall. Anteriorly the possible lattice organs in BM J 6221 lack all but a trace of the dark rim and the light central area typically measures $\sim 100 \mu \mathrm{m}$ in length and less in width (Fig. 1D). Probably, the dark rim corresponds to an area with a thicker, more heavily tanned or otherwise differentiated cuticle (Fig. 2).

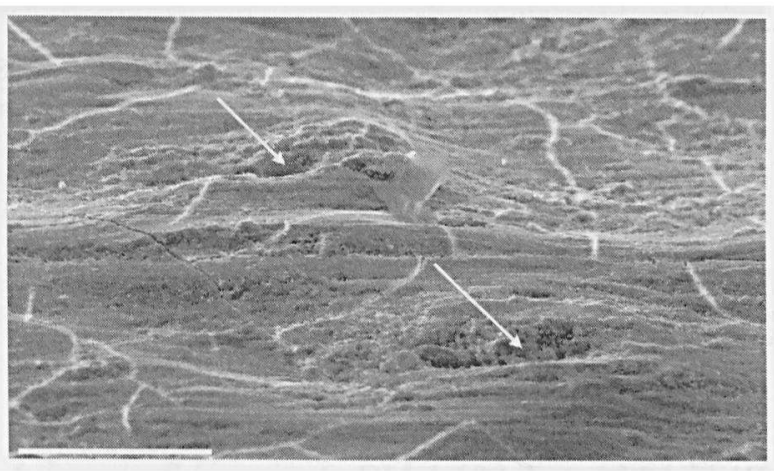

Fig. 2. Protozoea hilgendorfi. Anterior to the right. BM J 6221. SEM photograph. Oblique view of dorsal midline with a pair of possible lattice organs. Each consist of a central depression (arrows) more or less surrounded by low ridges. Note also tendency for lowered areas anterior and posterior to depression. Scale bar $=100 \mu \mathrm{m}$.

\section{Morphology of possible lattice organs in SEM}

\section{Pair 1}

Left: Covers an oval area of $140 \times 80 \mu \mathrm{m}$ (Fig. 3A). A club-shaped trench or depression of $90 \mu \mathrm{m}$ length is laterally surrounded by two longitudinally running ridges. Small lines demarcate the periphery outside of the ridges. The distance between the tops of the two ridges is $40-60 \mu \mathrm{m}$, being widest near the anterior end. From each ridge a steep but not vertical slope leads toward the more or less flat- 

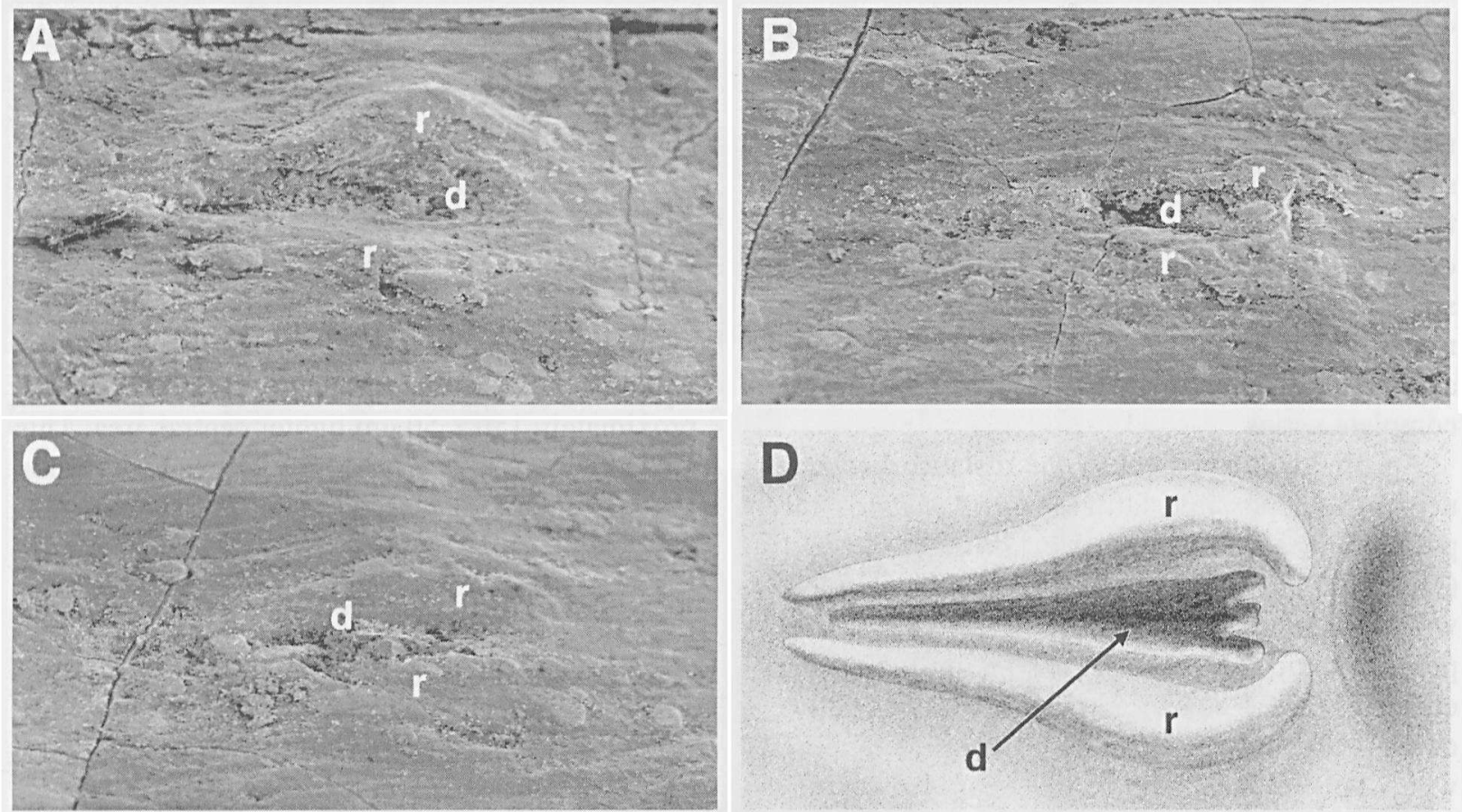

Fig. 3. Protozoea hilgendorfi. Anterior to the right. BM J 622-1. SEM photographs (A - C) and (D) line drawing showing reconstruction of possible lattice organ with two folds indicated in the anterior part of the depression. $r$, ridge; $d$, depression. Scale bar $=20 \mu \mathrm{m}$.

bottomed trench. Anteriorly the floor of the trench is $15 \mu \mathrm{m}$ wide, narrowing down to $5 \mu \mathrm{m}$ posteriorly.

Right: Covers approximately $140 \times 70 \mu \mathrm{m}$. Its outline resembles the previous. Less pronounced ridges surround the $\sim 100 \mu \mathrm{m}$ long depression, which has a wider anterior part and a more narrow and shallow posterior part. The floor of the anterior part is cast into a few distinct, mainly longitudinal folds.

\section{Pair 2}

Left: Dimensions $150 \times 80 \mu \mathrm{m}$ (Fig. 3B). Apparently the depression falls in several different parts. Anteriorly there seems to be a short shallow terrace with a bump-like short fold. This is followed by a deep, only $40 \mu \mathrm{m}$ long part of the trench that extends into the $60 \mu \mathrm{m}$ more shallow posterior region. The width narrows from $15 \mu \mathrm{m}$ to $10 \mu \mathrm{m}$. Weak folding of the floor occurs in both the deep part of the trench and the more shallow part. A groove is observed near the anterior margin.

Right: A $125 \mu \mathrm{m}$ long trench area surrounded by diminutive ridges (Fig $3 \mathrm{C}$ ). The floor of the up to $20 \mu \mathrm{m}$ wide trench shows some folding anteriorly, but a grainy substance obscures most of this territory especially towards the $5 \mu \mathrm{m}$ wide posterior end.

\section{Pair 3}

Left: Covers an oval area of $130 \times 80 \mu \mathrm{m}$. The ridges surround an at least $90 \mu \mathrm{m}$ long club-shaped trench that preserves traces of folds anteriorly. Near the anterior margin there is a diminutive indentation that could represent a pore.

Right: A $130 \times 60 \mathrm{~mm}$ long structure in which the median ridge is practically absent. Nevertheless, the remaining slopes delimit a trench of the usual shape. A short depression occurs near the 20 $\mu \mathrm{m}$ wide anterior margin followed by a raised area that may correspond to the short folds mentioned above. The posterior part of the trench is somewhat obscured by sediment and presents little evidence for the presence of a pore.

\section{Pair 4}

Left: Covers an area of $120 \times 50 \mu \mathrm{m}$. Not as clearly defined as previous due to sediment, but it includes ridges and a club-shaped trench. 
Right: The general outline is the usual, but sediment obscures details.

\section{Reconstruction of the morphology of a possible lattice organ}

An attempt to reconstruct the original morphology of the possible lattice organs of these Thylacocephala may be derived from the descriptions above (Fig. 3D). The tanned areas observed with light-microscopy to surround the possible lattice organs are not recognizable in SEM and are therefore not be included in the reconstruction. (Cuticle of a similar color occurs in connection with other structures such as the characteristic pit organs (Fig. 1B and F) or along the carapace margins, and may simply indicate a change in thickness or some other property of the cuticle).

An individual possible lattice organ from the posterior region of the carapace can therefore be recognized based on its general relief. It covers an elongated sub-oval area of approximately 120-150 $\mu \mathrm{m}$ parallel to the longitudinal axis of the animal and a width ranging from $60-80 \mu \mathrm{m}$. Superficially, each possible lattice organ consists of a central elongated trench flanked by low ridges. Though the ridges appear clearest along the 'long sides' of the trench, they could actually represent the remains of only one ridge completely encircling each trench. To the external side, the ridges gently grade into the carapace cuticle. On the internal side the slopes pass into the trench. The floor of the trench is situated below the external level of the ordinary carapace cuticle. Slopes also lead up from the floor of the trench to the carapace at both the anterior and posterior ends. The ridges seem to project up to 20 $\mu \mathrm{m}$ above the carapace surface in its immediate surroundings.

In most cases, the trench has a distinct club shape with the wider anterior part reaching $15-20 \mu \mathrm{m}$ while the width of the more narrow posterior $2 / 3$ of the trench predominantly is less than $10 \mu \mathrm{m}$. The total length of the floor is difficult to asses precisely because it grades into the carapace cuticle, but typically it surpasses $100 \mu \mathrm{m}$.

When not covered by sediment, the broader anterior part of the trench often appears folded. Typically there are one to a few small and short folds (Fig. AA and B). Slighter folds were observed, but rarely, in the narrow posterior part of the trench.

The search for associated pores did not yield a consistent result. There were no pores appearing in the same location in all investigated possible lattice organs. However, in a few cases pore-like grooves were observed, near both the posterior and the anterior end of the trench (Fig 4B and C). In other of the inspected possible lattice organs, however, these locations lacked recognizable pores (Fig 4A).

Additional oblong structures were noted in $P$. hilgendorfi (specimen BM J 622-1 and BM PI IC
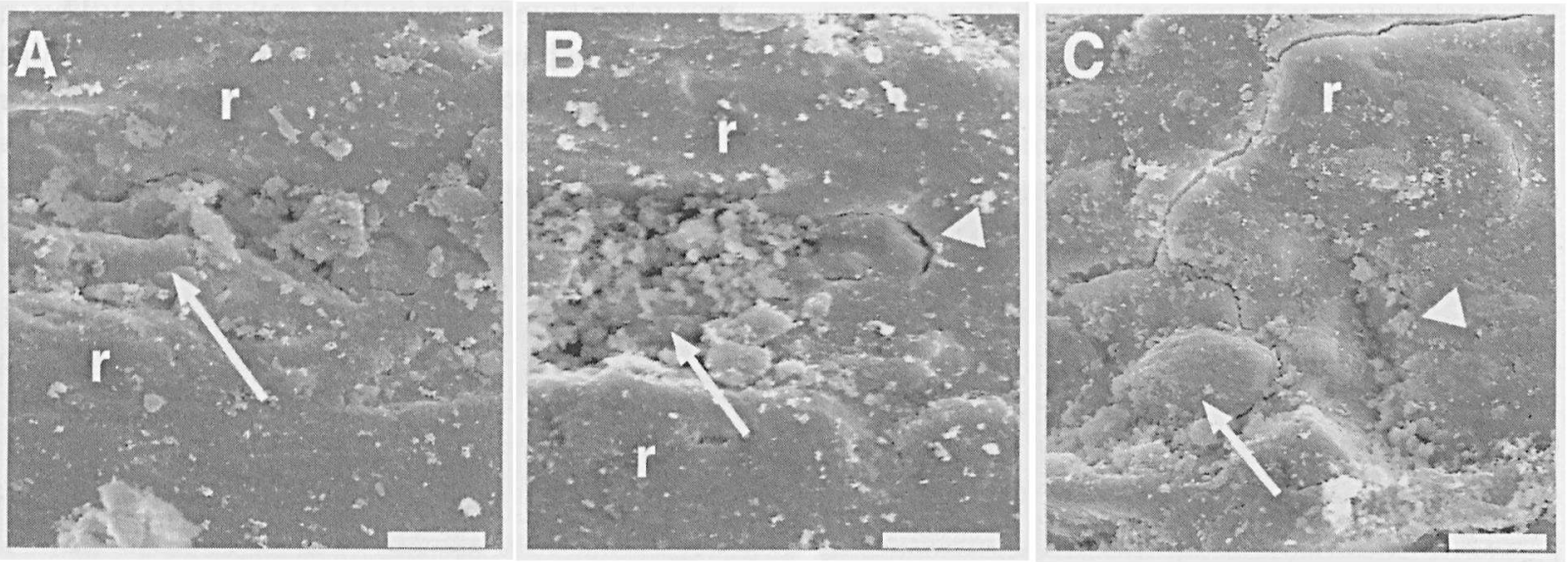

Fig. 4. Details of anterior part of possible lattice organs from Protozoea hilgendorfi. Anterior to the right. BM J 622-1 A, Folds (arrow). B, Fold (arrow) and pore-like slit (arrowhead). C, Short fold (arrow) and pore-like slit (arrowhead). r, ridge. Scale bars A and $\mathrm{B}=10 \mu \mathrm{m} ; \mathrm{C}=5 \mu \mathrm{m}$. 


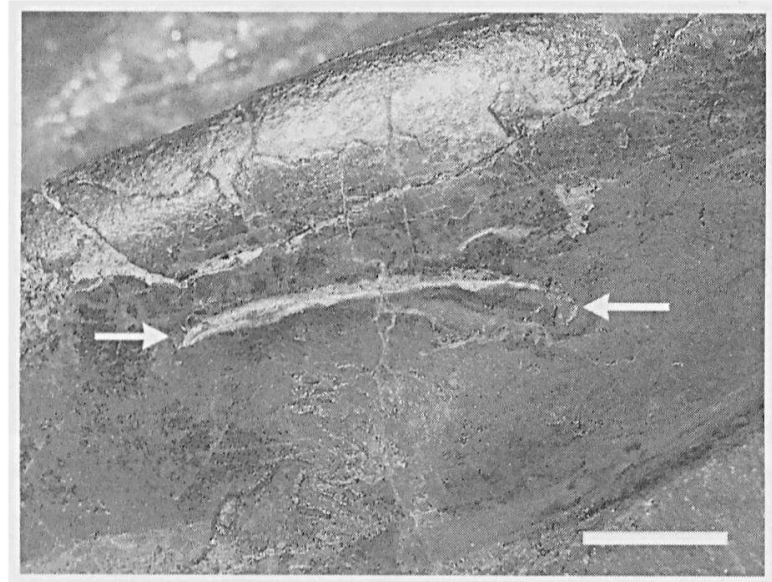

Fig. 5. Dollocaris ingens. MNHN R.50937. Anterior to the right. Arrows indicate start and end of an elongate structure occurring on the carapace. Scale bar $=2 \mathrm{~mm}$.

82 ) and probably in $P$. damesi (specimen BM IC 91-1). Reaching sizes around 500-600 $\mu \mathrm{m}$ they are considerably larger than adjacent possible lattice organs, though not dissimilar in consisting of two juxtapositioned longitudinal ridges. These oblong structures were found in only one pair per individual, situated anteriorly immediately ventral to the series of possible lattice organs in a bilaterally symmetrical arrangement (Fig. 1D). Furthermore, the carapace of Dollocaris also possesses a pair of elongate structures, albeit in a more ventral position; they are slightly curved and seemingly made up by two parallel ridges (Fig. 5).

\section{Discussion}

The position of the possible lattice organs close to the thylacocephalan dorsal midline resembles somewhat that of the lattice organs in the thecostracan Crustacea. However, the characteristic $2+3$ arrangement found in the latter was not observed in the examined Thylacocephala.

In a morphological comparison, it is immediately obvious that the reconstructed possible lattice organ described above does not correspond completely to any of the principal types of lattice organs occurring in the extant thecostracan crustaceans as described by Jensen et al. (1994a) and Høeg \& Kolbasov (2002). The possible lattice organs are very different from the 'pore field' type with the characteristic perforated surface (Fig. 6A). Such pore fields are autapomorphic for the thoracican and rhizocephalan thecostracans (Høeg \& Kolbasov 2002). However, thecostracan lattice organs of the second principal type do have a smooth cuticle seemingly 'folded' into one elongated keel that sits in a depression (Fig. 6B). This 'keel in a trough' type is considered more plesiomorphic within the Thecostraca, occurring in the Facetotecta (Høeg \& Kolbasov 2002) as well as in the Ascothoracida and the Acrothoracica (Jensen et al. 1994a). Lattice organs from both Acrothoracica and Facetotecta are more shallow with less pronounced keels than depicted in Fig. 6B (Jensen et al. 1994a; Høeg \& Kolbasov 2002). The possible lattice organ of the Thylacocephala resembles the plesiomorphic lattice organ type in having the same basic outline, $i$. e., elongated depression of a smooth cuticle with a tendency to display folds, as observed in its broader
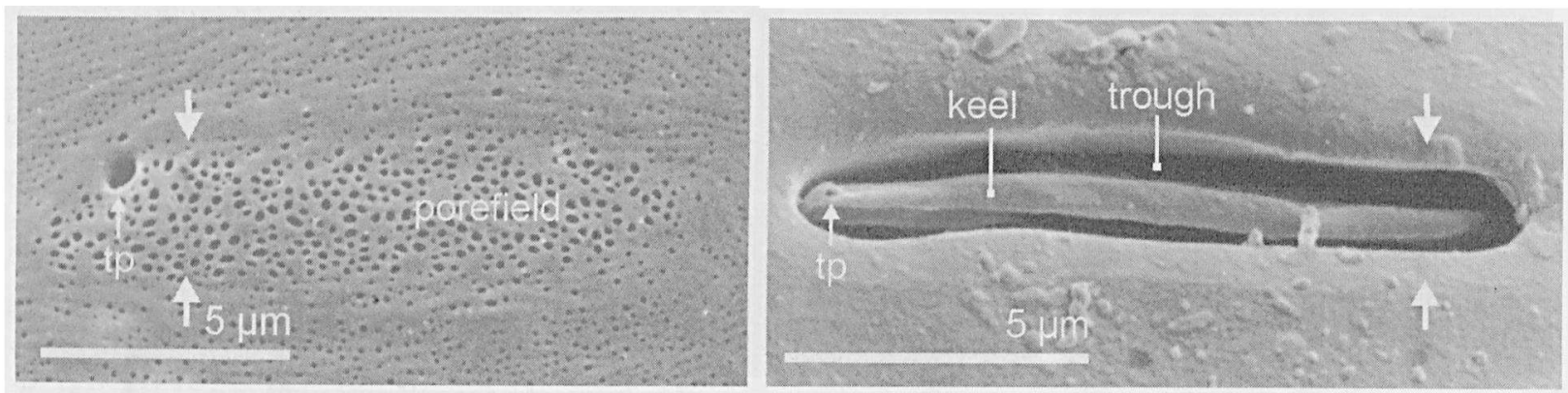

Fig 6. Examples of thecostracan lattice organs. A, 'Keel in a trough' type from Ascothoracida. B, 'Pore field' type from Thoracica (both from Høeg \& Kolbasov, 2002) tp, terminal pore. 
anterior region. These folds could represent the keel, but they do not present the same tight fitting keel sitting in a narrow depression. The ridges that surround the possible lattice organs may be comparable to the elevated rims surrounding the central area of lattice organs reported from some thecostracans. The lack of definitive evidence of terminal pores in the thylacocephalans is troubling. The smooth 'keel in a trough' type lattice organ always possess a terminal pore, whereas the terminal pore is absent from the apomorphic pore fields in some species (Jensen et al. 1994a). However, the lowered areas anterior and posterior to the possible lattice organs (Fig. 2) again bear resemblance to lattice organs from some thoracican thecostracans. Here the lattice organ includes an anterior concavity housing the terminal pore as well as a slight posterior concavity (Jensen et al. 1994a).

In general the possible lattice organs of the thylacocephalans are several times larger than the lattice organs of thecostracans. Perhaps this larger size could be viewed as an allometric consequence of a much larger body size. While thecostracan larval stages with lattice organs measure around $1 \mathrm{~mm}$ (Jensen et al. 1994a; Høeg \& Kolbasov 2002), the examined thylacocephalan fossils ranged from a few to eight $\mathrm{cm}$ to say nothing of other thylacocephalans; some like Dollocaris and Ostenocaris Arduini et al. 1982 surpass $20 \mathrm{~cm}$. In proportion to total body length, however, thecostracan lattice organs actually appear slightly larger than those of the thylacocephalans. Since lattice organs are evidently derived setae (Rybakov et al. in press) it is interesting to notice that chemosensory setae may reach a length of at least $2.0 \mathrm{~mm}$ in specimens of the decapod crustacean Homarus americanus (Milne-Edwards) with body sizes comparable to the protozoean thylacocephalans (Derby 1982).

On the other hand, the number of observed possible lattice organs clearly exceeds that of lattice organs in the Thecostraca, even if the 'extra' pore fields observed in some thecostracans (Jensen at al. 1994a) may reduce this difference. The different number of observed organs could depend on body size too, but may also be attributed to the fact that only certain small larval stages in thecostracans are equipped with lattice organs, while it is likely, though not proven, that the observed possible lat- tice organs occur in mature specimens of thylacocephalans.

Because of these morphological similarities, we might assume that the large and numerous possible lattice organs in Thylacocephala are really homologous to the lattice organs in the Thecostraca. This can argue for a relationship between the two groups. However, it can never serve to include the thylacocephalans within the Thecostraca sensu Grygier (1987) primarily because the highly conserved apomorphic pattern of $2+3$ lattice organs in Thecostraca is absent in the Thylacocephala.

If a sister group relationship is accepted, an opportunity to compare the body plan of the Thecostraca and the emerging information concerning the body plan of the Thylacocephala presents itself. Thecostracans have a comparatively short trunk consisting of no more than 11 segments including up to seven in the thorax. Such short bodies also occur in other crustaceans, which are often placed within the Maxillopoda (Schram 1986, but see also Schram \& Hof 1998). Because most of the adult thecostracans are highly modified for sessile or parasitic lifestyles, only few lend themselves to such a direct comparison. The thecostracan ascothoracid genus Synagoga Norman, 1888 has seven thoracic somites and four abdominal in addition to a typical crustacean cephalic region of five segments (Grygier 1983; 1984). The posterior end of a thylacocephalan body includes a battery of eight (sometimes even more) limb-bearing segments. This does not accord with any of the thecostracans. Furthermore, comparison with the wider array of maxillipodans presents similar problems. To force thylacocephalans into these more inclusive groups would require a postulated combination of elements that is difficult to envision at this time, viz., the fusing of two short tagmata to form in some way the 8+ segments of the posterior thylacocephalan body region. At present, the Thylacocephala cannot convincingly dispute the potential sister group relationship between Thecostraca and the Tantulocarida as well as Bredocaris (Walossek \& Müller 1998).

Attempting to see thylacocephalans in an ancestral role with respects to thecostracans also demands large hypothetical rearrangements in the body plan. Presently, it appears that the thylacocephalans may have had at least three pairs of limbs between the 
mandible and the posterior limb battery (Polz 1993, Schram 1990, Lange et al. 2001). This suggests that thylacocephalans had a maxilliped, but speculation on homology to the maxillipeds in Thecostraca seems premature. Maxillipeds do occur in some maxillopodans, but together with a correspondingly reduced number of remaining thoracic limbs (Grygier 1983, Schram 1986). Again, the number of remaining limbs would seem too low when compared to the $8+$ battery in thylacocephalans.

Finally, though the oblong structures (Fig. 1D) and the more dorsal possible lattice organs in $P$. hilgendorfi are similar, it is more interesting that the former are also similar to the more ventral and elongate structures on the carapace of Dollocaris (Fig. 5). Yet another elongate and slightly curved structure has been reported in a presumed lateral position on the carapace of the Silurian marine fossil arthropods, Dictyocaris Salter 1860 (see Brugghen: 1995, fig 1a). Dictyocaris reached the formidable length of at least $30 \mathrm{~cm}$, but because corresponding limbs, eyes, gills etc. are presently unknown for this taxon, the phylogenetic position of these mysterious arthropod carapaces remains elusive (Van den Brugghen, 1995; Rolfe 1969). The identification of such, elongated, carapace structures constitutes a first indication of a probable thylacocephalan affinity for Dictyocaris. This begs for a new investigation of Dictyocaris especially in regard to cuticular structures.

In summary, this is the first time that lattice, or possible lattice, organs have been found outside the Thecostraca sensu Grygier. However, the structural and topographic differences between possible lattice organs and lattice organs may eventually tell us more about the plesiomorphic condition in a possible thecostracan out-group than posit any close phylogenetic relationship. In addition, this harkens back to the original description and interpretation of the thylacocephalan Ostenocaris cypriformis (Arduini et al. 1980), which postulated a barnacle affinity in the context of thylacocephalans representing "the big cyprid". We might ask, has the history of this group come full circle?

\section{Acknowledgement}

We thank Jan van Arkel for graphic assistance. Prof. Derek Briggs and Dr. Jens Høeg offered valuable suggestions for improving the manuscript. We are further indebted to Dr. Jens Høeg for permitting us to use the illustrations of thecostracan lattice organs (Fig. 6).

\section{References}

Arduini P, Pinna G, Teruzzi G. 1980. A new and unusual lower cirripede from Osteno in Lombardy: Ostenia cypriformis n. g. n. sp. (preliminary note) Atti della Societã Italiana di Scienze Naturali e del Museo Civico di Storia Naturale di Milano 121: 360-370.

Briggs DEG, Rolfe WDI. 1983. New Concavicarida (new order: ?Crustacea) from the Upper Devonian of Gogo, Western Australia, and the palaeoecology and affinities of the group. Spec. Papers in Palaeontol. 30: 249-276.

Derby CD. 1982. Structure and function of cuticular sensilla of the lobster Homarus americanus. J. Crust. Biol. 2(1): 121.

Elfimov AS. 1986. Morphology of the carapace of cypris larva of the barnacle Heteralepas mystacophera. Soviet J. Mar. Biol. 12: 152-156.

Grygier MJ. 1983. Ascothoracida and the unity of Maxillopoda. Crust. Issues 1: 73-104.

Grygier MJ. 1984. Comparative morphology and ontogeny of the Ascothoracida, a step toward a phylogeny of the Maxillopoda. Ph.D. dissertation, University of California San Diego, $\mathrm{xxi}+417 \mathrm{pp}$.

Grygier MJ. 1987. New records, external and internal anatomy, and systematic position of Hansen's Y larvae Crustacea: Maxillopoda: Facetotecta. Sarsia. 72: 261-278.

Høeg J, Hosfeld B, Jensen PG. 1998. TEM studies on the lattice organs of cirripede cypris larvae (Crustacea, Thecostraca, Cirripedia). Zoomorph. 118: 195-205.

Høeg JT, Kolbasov GA. 2002. Lattice organs in y-cyprids of the Facetotecta and their significance in the phylogeny of the Crustacea Thecostraca. Acta Zool. 83: 67-79.

Itô T, Grygier MJ. 1990. Descriptions and complete larval development of a new species of Baccalaureus (Crustacea: Ascothoracida) parasitic in a zoanthid from Tanabe Bay, Honshu, Japan. Zool. Sci. 7: 485-515.

Jensen PG, Moyse J, Høeg JT, Al-Yahya H. 1994a. Comparative SEM studies of lattice organs: Putative sensory structures on the carapace of larvae from Ascothoracida and Cirripedia (Crustacea Maxillopoda Thecostraca), Acta Zool, 75: 125-142.

Jensen PG, Høeg JT, Bower S, Rybakov AV. 1994b. Scanning electron microscopy of lattice organs of the cyprids of the Rhìzocephala Akentrogonida (Crustacea Cirripedia). Can. J. Zool. 77: 1018-1026.

Lange S, Hof CHJ, Schram FR, Steeman FA. 2001. New genus and species from the Cretaceous of Lebanon links the 
Thylacocephala to the Crustacea. Palaeontol. 44: 905-912. Míkulic DG, Briggs DEG, KIuessendorf J, 1985. A new exceptionally preserved biota from the Lower Silurian of Wisconsin, U.S.A. Phil. Trans. R. Soc. Lond. B 311: 171-180.

Pinna G, Arduini P, Pesarini C, Teruzzi G. 1982. Thylacocephala: una nuova Classe di Crostacei fossili. Ati della Societa italiana di Scienze naturali e del Museo Civico di Storia Naturale di Milano 123: 469-482.

Pinna G, Arduìni P, Pesarini C, Teruzzi G. 1985. Some controversial aspects of the morphology and anatomy of Ostenocaris cypriformis (Crustacea, Thylacocephala). Trans. Roy. Soc. Edinburgh 76: 373-379.

Polz H. 1993 Zur metamerie von Clausocaris lithographica (Thylacocephala, ?Crustacea). Archaeopteryx 11: 105-112.

Rolfe WDI. 1969. Phyllocarida, p. R296-R331. In: Moore RC, ed. Treatise on Invertebrate Paleontology, Part R, Arthropoda 4, volume 1. Geol. Soc. Am. \& Kansas Press Lawrence.

Rolfe WDI. 1985. Form and function in Thylacocephala, Conchyliocarida and Concavicarida (?Crustacea): a problem of interpretation. Trans. Roy. Soc. Edinburgh 76: 391-399.

Rolfe WDI. 1992. Not yet proven Crustacea: the Thylacocephala. Acta Zool. 73: 30l-304.

Rybakov AV, Høeg JT, Jensen PG, Kolbasov GA. In press. Chemoreceptive Lattice Organs in Cypris Larvae develop from Naupliar Setae (Thecostraca: Cirripedia, Ascothoracica and Facetotecta). Zool. Anz.

Schram FR. 1986. Crustacea. New York: Oxford University Press.

Schram FR. 1990. On Mazon Creek Thylacocephala. Proc. San Diego Soc. Nat. Hist. 3: 1-16.

Schram FR, Hof CHJ, and Steeman FA. 1999. Thylacocephala
(Arthropoda: Crustacea?) from the Cretaceous of Lebanon and implications for thylacocephalan systematics. Palaeontol. 42. 769-797.

Schram FR, Hof CHJ. 1998. Fossils and interrelationships of major crustacean groups. 233-302. In Edgecombe G. (ed.), Arthropod fossils and phylogeny : New York: Columbia University Press.

Secretan S. 1983: Une nouvelle classe fossile dans la superclass des crustacés: Conchyliocarìda. $C R$ Acad. Sci. Paris, 296: 437-439.

Secretan S. 1985: Conchyliocarida, a class of fossil crustaceans: relationships to Malacostraca and postulated behaviour. Trans. Roy. Soc. Edinburgh 76: 381-389.

Secretan S, Riou B. 1983: Un groupe énigmatique de crustacés: ses représentants du Callovien de la Voulte-sur-Rhone. Ann. Paléont., 69: 59-97.

Van den Brugghen W. 1995. Dictyocaris, een enigmatisch fossiel uit het Siluur, Grondboor en Hamer, 49: 18-22.

Van den Brugghen W, Martill DM, Schram FR. 1997. The fossil Ainiktozoon is an arthropod. Nature 385: 589-590.

Walossek D, Herg TH, Shirley TC. 1996. Larval development of the rhizocephalan cirripede Briarosaccus tenellus (Maxillopoda: Thecostraca) reared in the laboratory: a scanning electron microscopic study. Hydrobiologia 328: 9-47.

Walossek D, Müller KJ. 1998. Early Arthropod Phylogeny in Light of the Cambrian "Orsten" Fossils. 185-232. In Edgecombe $\mathrm{G}_{\mathrm{x}}$ (ed.). Arthropod fossils and phylogeny : New York: Columbia University Press.

Received: 16 April 2002 